\title{
COVID-19 pandemic leading to unidentified, silent-pandemic of vitamin D deficiency in young children: a case report
}

\author{
Manasvee Dewan*, Neha Sharma, Pragyan Swagatika Panda, Priyanka Banerjee
}

Department of Microbiology, Janakpuri Super Speciality Hospital Society, New Delhi, India

Received: 21 October 2021

Accepted: 18 November 2021

\section{*Correspondence:}

Dr. Manasvee Dewan,

E-mail: dewanmanasvee@gmail.com

Copyright: ( $)$ the author(s), publisher and licensee Medip Academy. This is an open-access article distributed under the terms of the Creative Commons Attribution Non-Commercial License, which permits unrestricted non-commercial use, distribution, and reproduction in any medium, provided the original work is properly cited.

\begin{abstract}
Vitamin D is a pro hormone needed for the homeostasis of calcium and phosphorus in the body. This state is crucial for maintaining metabolism, nerve conduction and general cellular functions in the body. Coronavirus disease 2019 (COVID-19) pandemic has led to long-term lockdowns. Schools are closed, people are confined to their homes and outdoor activities are at a halt. This has led to rise in cases of vitamin D deficiency (particularly in infants and toddlers) which is going un-noticed and can further lead us to another pandemic of non-communicable disease - vitamin D deficiency. We have presented a case report of healing rickets in a 19-month-old toddler. We aim to highlight this under-diagnosed and ignored vitamin deficiency that can affect the overall health of our younger generation in this COVID-19 era.
\end{abstract}

Keywords: COVID-19, Pandemic, Vitamin D, Deficiency, Rickets

\section{INTRODUCTION}

Vitamin D stands out from other essential vitamins in preventing growth retardation, maintaining a healthy metabolism and absorption of other vitamins and minerals in the body. ${ }^{1}$ There have been reports of vitamin D preventing infections, auto-immune diseases, Type 1,2 diabetes, cancer and osteoporosis in later life. ${ }^{1,2}$ It is indispensible for the growth of infants and toddlers. Exclusive and partially-breastfed babies need 400IU units of vitamin D every day. ${ }^{3}$ The major sources of vitamin D are dietary and sunlight. ${ }^{4}$ Sunlight converts 7dehydrocholesterol in the skin into vitamin D. This conversion is significantly influenced by different weather, time of day, latitude, altitude, air pollution, skin pigmentation, sunscreen use, passing through glass and plastic, and aging. 5,6

It's been more than a year now that we are restricted to move out as before and outdoor activities, visits to parks, etc. are rare. This lockdown state worldwide is significantly affecting our vitamin D levels; infants and toddlers are at the greatest loss in particular. Inadequate sun exposure might be the major factor responsible.

\section{CASE REPORT}

We have reported a case of healing rickets in a 19-monthold toddler at our medical facility. The patient presented with a history of weakness since 2-3 days. As per the information given by parents, he was doing fine 3 days back when he had 5-6 episodes of teething diarrhoea. The patient developed weakness and was slightly lethargic. His gait was limping after sustaining a fall while running. Xray was done and the diagnosis of healing rickets was confirmed by orthopedician. There was no generalised chronic weakness, no delay in milestones. Eruption of teeth was in synchronisation with his age. Height and weight were in normal range of his age. There was no widening of ankle joints or distal radius present. His vital signs were stable. His was an alert, playful, developmentally appropriate child. His head/neck, cardiac, 
respiratory, gastrointestinal, genitourinary, musculoskeletal and neurological examinations were within normal limits. There was no significant family history. His birth weight was $2.43 \mathrm{~kg}$ and $44.5 \mathrm{~cm}$ height. He was a full-term baby with 37 weeks of gestation. Vitamin D supplements were given religiously right from the start as per the advice of pediatrician and baby was breastfed for 6 months. During the period of lactation, the mother took adequate vitamin D supplements along with calcium and iron supplements. After 6 months of age, the baby was started gradually on solid diet that included egg yolk every alternate day and milk intake was adequate. At 8 months of age, his weight was $8.2 \mathrm{~kg}$, height $69 \mathrm{~cm}$ and head circumference was $43.5 \mathrm{~cm}$ which were all in the normal range as per his age. There was mild sclerosis with cupping of bones under lateral and antero-posterior view of knee joints of both legs, see Figure $1 .^{1}$ No other bony lesion was present. The baby was confined to indoors since March, 2020 due to COVID-19 pandemic which seems to be the only risk factor present.

This is to highlight that unprecedented COVID-19 pandemic can further lead to such cases of chronic and severe vitamin D deficiency and there might be more silent cases in the community. This state of unexposed children can lead to rise of another public health problem which cannot be overlooked. During this COVID-19 pandemic period, the major focus is on the correlation of vitamin D status and prognosis of COVID-19 disease. This concern of consistently decreasing levels of vitamin $\mathrm{D}$ due to confinement at home is probably being ignored.

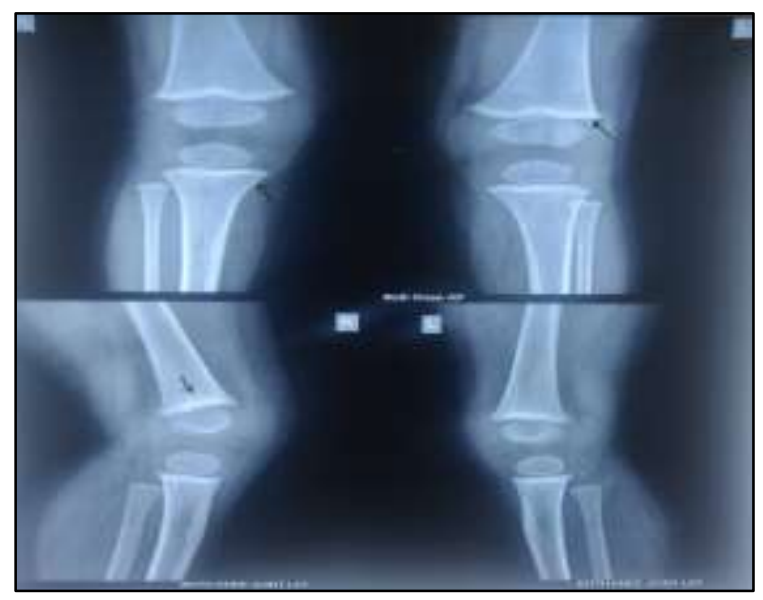

Figure 1: Radiograph showing sclerosis and cupping of bones.

\section{DISCUSSION}

A normal level of vitamin D is labelled as a $(25(\mathrm{OH}) \mathrm{D})$ concentration $\geq 20 \mathrm{ng} / \mathrm{mL}(50 \mathrm{nmol} / \mathrm{l})$. Levels less than 12 $\mathrm{ng} / \mathrm{mL}(30 \mathrm{nmol} / \mathrm{l})$ is considered as vitamin deficiency while levels between 12 to $20(30-50 \mathrm{nmol} / \mathrm{l})$ is vitamin $\mathrm{D}$ insufficiency. ${ }^{7}$ Consistent decrease in normal levels of vitamin $\mathrm{D}$ is attributed to development of vitamin $\mathrm{D}$ deficiency and rickets in children. Rickets is the failure of bones to get mineralised. Nutritional deficiency, lack of sun exposure, hereditary, malabsorption and renal disease can be some of the causes of vitamin D deficiency. ${ }^{8}$ Vitamin D deficiency is prevalent worldwide and recently, during this pandemic period there has been a surge in the cases.

In a study by Wong et al impact of COVID-19 pandemic on vitamin $\mathrm{D}$ levels in infants and toddlers has been studied wherein 303 infants and toddlers were divided in two groups of pre and post outbreak period. Serum 25hydroxyvitamin $\mathrm{D}(25(\mathrm{OH}) \mathrm{D})$ levels were checked over a period of time. There was no immediate effect in the levels of $(25(\mathrm{OH}) \mathrm{D})$ levels in infants and toddlers after COVID19 pandemic but when the results were studied over a period of months, it was noted that the levels kept on decreasing; the magnitude of decline was significantly high in young infants of 2-6 months of age in the pre outbreak period. Infants and toddlers in the post-outbreak group had a notably lower serum $(25(\mathrm{OH}) \mathrm{D})$ level than those in the pre-outbreak group, particularly for those aged 7-24 months. This could be due to the reason that older infants may have other ways like outdoor activities and sun exposure to obtain vitamin D during the pre-outbreak period. ${ }^{9}$

In a similar study conducted in China on children who underwent health check-ups between March 1 and June 30, 2020, and those over the equivalent period between 2017 to 2019 ( $\mathrm{n}=3600)$. (25(OH) D) levels and the proportion of children with vitamin D deficiency were compared between the two observation periods. It was concluded that confinement of children at homes due to pandemic had affected the vitamin D levels. The proportion of children with vitamin D deficiency was higher in 2020 than in 2017 to $2019 .^{10}$

In another study by Kang et al, 226 children aged 4 to 18 years were studied for different growth parameters. In the study, serum $(25(\mathrm{OH}) \mathrm{D})$ levels were accessed in preCOVID-19 and post-COVID-19 periods. Pre-COVID-19 was one year period before school closure (2-03-2020) and post-COVID-19 was 6 months period after 2 nd of March, 2020. It was observed that after six months of school closure, home confinement of children, serum $(25(\mathrm{OH}) \mathrm{D})$ levels decreased significantly. ${ }^{11}$

Rise in the cases of vitamin D deficiency and rickets are a resultant of long-term indoor stay which has lead to no exposure to sunlight. The alarming state is that this essential vitamin deficiency has long-term health consequences in young population and this disease is probably under-diagnosed and majorly ignored. In India, the prevalence rate of vitamin D deficiency ranges from 50 to $94 \% .{ }^{12}$ Recently in India, there have been reports of rise in rickets cases in a hospital in the capital. 12 cases of rickets in the age group of 2-12 years have come into account. The lack of sun exposure and prolonged indoor stay in the last one year has been concluded the reason responsible. ${ }^{13}$ 
With the current state of affairs, this is further going to increase leading to a silent-pandemic in young children. Previously, mal-nourished and poor families used to come with the disease but now due to COVID-19 the picture has changed; affluent families are coming up with the problem. ${ }^{13,14}$ In urbanised setups where space constraints are present. Glass absorbs UV B rays, thus, making the process inefficient. Application of sunscreens also bars the formation of vitamin D.

Awareness and education of the community is the first step in preventing the problem and uprooting the root cause. Knowledge of the early warning signs should be given like child remains fussy and restless, there is lack of sleep that is might be due to bone pain, retarded growth, delayed crawling, sitting or walking. Painful and enlarged bones are possible, along with swelling at the joints such as wrists and ankles. Muscles become weak. Abnormal development and decay of teeth may also occur. In older children, it leads to bowed-legs. ${ }^{15}$ The masses have to be made aware about early signs and symptoms and preventive measures through different media available and accessible to population for the prevention of this public health problem.

\section{CONCLUSION}

Awareness of community in-total about dietary requirements of infants, early warning signs along with mandatory sun-exposure has to be done. The importance of sunlight exposure is usually underrated. Thus, to conclude, we have to get out of our homes with all COVID19 appropriate behaviour and precautions and bathe in direct sunlight to prevent our growing young generation from disease and morbidity. Individual and community based measures should be enforced as soon as possible to prevent the aggravation of the problem.

Funding: No funding sources Conflict of interest: None declared

Ethical approval: Not required

\section{REFERENCES}

1. Casey CS, Slawson DC, Neal LR. Vitamin D supplementation in infants, children, and adolescents. American family physician. 2010;81(6):745-8.

2. Folsom LJ, Linda A. DiMeglio. Recommendations released on prevention, management of rickets. American academy of Paediatrics. Available at: https://www.aappublications.org/news/2017/02/10/R ickets021017. Accessed on 20 May 2021.

3. Centers for Disease Control and Prevention. Vitamin D. 2021. Available at: https://www.cdc.g ov/breastfeeding/breastfeeding-special-circums tances/diet-and-micronutrients/vitamin-d.html. Accessed on 20 May 2021.
4. National Institutes of Health Office of Dietary Supplements. Vitamin D. Available at: https://ods.od.nih.gov/factsheets/VitaminDHealthProfessional/. Accessed on 20 May 2021.

5. Wacker M, Holick MF. Sunlight and Vitamin D: A global perspective for health. Dermatoendocrinol. 2013;5(1):51-108.

6. Nair R, Maseeh A. Vitamin D: The "sunshine" vitamin. Journal of pharmacology \& pharmacotherapeutics. 2012;3(2):118-26.

7. Dawson-Hughes BD. Patient education: Vitamin D deficiency (Beyond the Basics) UpToDate ${ }^{\circ}$. Available at: https://www.uptodate.com/ contents/vitamin-d-deficiency-beyond-the-basics /print. Accessed on 20 May 2021.

8. Nield LS, Mahajan P, Joshi A, Kamat D. Rickets: not a disease of the past. American family physician. 2006;74(4):619-26.

9. Wong RS, Tung KTS, So HK, Wong WHS, Wong SY, Tsang HW et al. Impact of COVID-19 Pandemic on Serum Vitamin D Level among Infants and Toddlers: An Interrupted Time Series Analysis and before-and-after Comparison. Nutrients. 2021;13:1270.

10. Yu L, Ke HJ, Che D, Luo SL, Guo Y, Wu JL. Effect of Pandemic-Related Confinement on Vitamin D Status Among Children Aged 0-6 Years in Guangzhou, China: A Cross-Sectional Study. Risk Manag Healthc Policy. 2020;13:2669-75.

11. Kang HM, Jeong DC, Suh BK, Ahn MB. The Impact of the Coronavirus Disease-2019 Pandemic on Childhood Obesity and Vitamin D Status. Journal of Korean medical science. 2021;36(3):e21.

12. Aparna P, Muthathal S, Nongkynrih B, Gupta SK. Vitamin D deficiency in India. J Family Med Prim Care. 2018;7:324-30.

13. Rickets cases rising since last year, kids of affluent families getting afflicted: Delhi hospital Times of India. 2021. Available at: https://timesofindia.indiatimes.com/city/delhi/rickets -cases-rising-since-last-year-kids-of-affluentfamilies-getting-afflicted-delhi. Accessed on 20 May 2021.

14. GR, Gupta A. Vitamin D deficiency in India: prevalence, causalities and interventions. Nutrients. 2014;6(2):729-75.

15. National Organization for Rare Disorders (NORD). Vitamin D Deficiency Rickets. 2020. Available at: https://rarediseases.org/rare-diseases/ricketsvitamin-d-deficiency/. Accessed on 20 May 2021.

Cite this article as: Dewan M, Sharma N, Panda PS, Banerjee P. COVID-19 pandemic leading to unidentified, silent-pandemic of vitamin D deficiency in young children: a case report. Int J Community Med Public Health 2021;8:6068-70. 